\title{
COMPOSTAGEM DA FRAÇÃO SÓLIDA DA ÁGUA RESIDUÁRIA DE SUINOCULTURA
}

\author{
MARCO A. P. ORRICO JÚNIOR ${ }^{1}$, ANA C. A. ORRICO ${ }^{2}$, JORGE DE LUCAS JÚNIOR ${ }^{3}$
}

RESUMO: Avaliar o desenvolvimento do processo de compostagem utilizando como substrato à fração sólida da água residuária de suinocultura foi o objetivo deste trabalho. Para a obtenção da fração sólida, a água residuária de suinocultura foi submetida ao peneiramento, utilizando-se de peneira com malha de 1 milímetro. Após separação, a fração sólida foi utilizada para a confecção de três leiras de compostagem, em pátio com piso de concreto e cobertura plástica. Durante a compostagem da fração sólida da água residuária de suinocultura, foram avaliados: temperatura, reduções de sólidos totais (ST), sólidos voláteis (SV), demanda química de oxigênio (DQO), carbono orgânico, matéria orgânica compostável (MOC), matéria orgânica resistente à compostagem (MORC), números mais prováveis (NMPs) de coliformes totais e coliformes termotolerantes, além do volume e dos teores de nutrientes no composto. A compostagem mostrou-se eficiente no tratamento da fração sólida da água residuária de suinocultura devido à elevada minimização do poder poluente dos dejetos, observando-se reduções de $71,24 \%$ nos teores de ST, $64,55 \%$ no volume, $56,89 \%$ no teor de DQO e 56,89\% na MOC. Foram verificadas reduções de $100 \%$ nos NMPs de coliformes totais e termotolerantes, o que possibilita seu uso como adubo orgânico.

PALAVRAS-CHAVE: coliformes, temperatura, redução de sólidos.

\section{SOLID FRACTION COMPOSTING OF RESIDUAL WATER FROM PIG FARMS}

\begin{abstract}
This work aimed to evaluate the development of the composting process by using the solid fraction of residual water from a pig farm. To obtain the solid fraction, the residual water was sewed in a $1 \mathrm{~mm}$ screen sew. After separation, the solid fraction was used to form three composting piles, on a patio with concrete floor and plastic cover. During composting the solid fraction of residual water from pig farms was monitored: temperature, total solids reduction (TS), volatile solids (VS) chemical demand for oxygen (CDO), organic carbon, compostable organic matter (COM), organic matter resistant to composting (OMRC), most probable numbers (MPN) of total coliforms and fecal coliforms, as well as volume and quality of the compost. The composting showed to be efficient for treatment of the solid fraction of residual water from pig farms because of the high reduction of manure polluting potential, which reduction of $71.24 \%$ of TS contents, $64.55 \%$ of volume, $56.89 \%$ of CDO and $56.89 \%$ COM. Reductions of $100 \%$ in MPN total coliforms and fecal coliforms were observed, what allows its use as organic fertilizer.
\end{abstract}

KEYWORDS: coliforms, temperature, reduction of solids.

\section{INTRODUÇÃO}

A produção de suínos gera consideráveis quantidades de dejetos, que são caracterizados pelos elevados teores de matéria orgânica e nutrientes. Segundo levantamentos apresentados na literatura, um suíno chega a excretar $6 \%$ do seu peso vivo, ao dia, em dejeto fresco, que, na maioria das vezes, é coletado na forma líquida e aplicado diretamente no solo. Essa aplicação prolongada, aliada ao aumento do número de animais produzidos por área, pode levar a problemas como eutrofização de corpos de água, contaminação fecal, liberação de metano e de outros gases indesejáveis para a atmosfera.

\footnotetext{
${ }^{1}$ Zootecnista, Doutorando em Zootecnia, Faculdade de Ciências Agrárias e Veterinárias - UNESP, Jaboticabal - SP, marcoorrico@yahoo.com.br

${ }^{2}$ Zootecnista, Profa. Adjunta, Faculdade de Ciências Agrárias - UFGD, Dourados - MS, anacarolamorim@ hotmail.com

${ }^{3}$ Eng $^{\circ}$ Agr $^{\circ}$, Prof. Titular, Faculdade de Ciências Agrárias e Veterinárias - UNESP, Jaboticabal - SP, jlucas@ @ fcav.unesp.br

Recebido pelo Conselho Editorial em: 19-3-2008

Aprovado pelo Conselho Editorial em: 16-9-2009
}

Eng. Agríc., Jaboticabal, v.29, n.3, p.483-491, jul./set. 2009 
O uso excessivo de água na limpeza das instalações de suínos leva à formação de efluente com baixa concentração de sólidos, sendo indicados, nessas condições, os sistemas anaeróbios de tratamento (biodigestores e/ou lagoas de estabilização). RICO et al. (2006) recomendam que seja feita a separação de sólidos antes do tratamento da água residuária em biodigestores, a fim de tornar o sistema mais eficiente (maior produção de biogás por $\mathrm{kg}$ de sólido), rápido (menor tempo de retenção hidráulica) e econômico. Essa melhora no sistema ocorre porque, durante o processo de separação da fração sólida, ficam retidas as estruturas de difícil degradação, compostas por frações insolúveis, fibras resistentes à degradação e partículas muito grandes.

Quando se utiliza um sistema de separação de sólidos do efluente, é necessário ter em mente que a fração sólida retida ainda tem elevado poder poluente e necessita de tratamento adequado, antes de ser destinado no meio ambiente.

Sendo assim, a compostagem seria uma forma de tratar a fração sólida (menos degradável) dos dejetos, restando como produto final um composto orgânico. LO et al. (1993) obtiveram excelentes resultados após submeter a fração sólida dos dejetos de suínos à compostagem com e sem a adição de resíduos vegetais.

A compostagem é uma das técnicas mais antigas empregadas no tratamento e na reciclagem dos dejetos gerados na produção animal. A facilidade de condução e os baixos custos para o desenvolvimento do processo têm justificado sua adoção (ORRICO et al., 2007). As vantagens da compostagem destacadas por ZHU (2007) foram: reciclagem dos elementos com interesse, redução do volume inicial de resíduos, degradação de substâncias tóxicas e/ou patógenos e produção de energia de forma mais disponível.

Esse sistema de reciclagem dos nutrientes é uma forma de acelerar a decomposição da matéria orgânica em relação ao que ocorreria no meio ambiente, melhorando as condições de atividade dos microrganismos (bactérias e fungos). Nesse processo, na fase termofílica ativa, há proliferação de microrganismos exotérmicos (aumento da temperatura da massa) com efetivo poder na destruição de patógenos e sementes de plantas daninhas.

ZHU et al. (2004) efetuaram a compostagem dos dejetos de suínos, coletados por raspagem, em associação com palha de arroz, nas proporções de 66 e 14\%, respectivamente. As leiras foram manejadas em três diferentes sistemas de aeração: aeração contínua, 4 horas por dia, a partir do quarto dia; aeração passiva, e aeração induzida, sempre que a temperatura na leira atingisse valores superiores a $60^{\circ} \mathrm{C}$. Aos 49 dias do início da compostagem, foram observadas reduções de 61,88 ; 48,07 e 50,53\% nas quantidades de matéria seca enleirada, em leiras manejadas com aerações contínua, passiva e induzida, respectivamente. As maiores temperaturas foram alcançadas em leiras com aeração induzida, e as menores, em leiras com aeração passiva. A partir do terceiro dia de compostagem, não foi detectada a presença de E. coli, e após 63 dias do início do processo, não foram encontrados ovos de helmintos. A maturação do composto foi verificada aos 49 dias.

Os avanços conseguidos na suinocultura, como um todo, indicam que os números que correspondem ao crescimento da atividade de suinocultura, tanto na produção de carne como na de dejetos, merecem ser analisados sob aspectos que se relacionam aos ganhos de mercado e às perdas e à degradação de recursos naturais.

Com base no exposto, o objetivo do trabalho foi avaliar a eficiência do processo de compostagem no tratamento da fração sólida da água residuária de suinocultura retida por meio do peneiramento, no que diz respeito à qualidade do processo e do composto final.

\section{MATERIAL E MÉTODOS}

A pesquisa foi desenvolvida no Laboratório de Biodigestão Anaeróbia, do Departamento de Engenharia Rural, com os dejetos coletados no Setor de Suinocultura, ambos pertencentes à Faculdade de Ciências Agrárias e Veterinárias - FCAV/UNESP, Jaboticabal - SP. 
A água residuária de suinocultura foi preparada por meio da mistura de água e dejeto de suínos, estabelecendo-se que o teor de sólidos totais (ST) se mantivesse entre 2,0 e 2,5\%. Esse substrato foi submetido ao peneiramento, empregando-se peneira de malha quadrada de $1 \mathrm{~mm}$, sendo a fração sólida retida utilizada para a confecção de três leiras de compostagem. Na Tabela 1, estão apresentados os valores de volume e massa de matéria natural (MN), sólidos totais ST e sólidos voláteis (SV) do material retido na peneira, que foram utilizados como substrato para o processo de compostagem.

TABELA 1. Volume e massa de matéria natural (MN), sólidos totais (ST) e sólidos voláteis (SV) do material retido na peneira, utilizados na confecção das leiras de compostagem. Volume and mass of matter (MM), total solids (TS) and volatile solids (VS) of the material retained on the sieve, used in the manufacture of compost piles.

\begin{tabular}{ccccc}
\hline \multirow{2}{*}{ Leira } & Volume & MN & ST & SV \\
\cline { 3 - 5 } & $\left(\mathrm{m}^{3}\right)$ & & $\mathrm{kg}$ & \\
\hline 1 & 0,426 & 341,0 & 88,0 & 76,0 \\
2 & 0,426 & 342,0 & 89,0 & 77,0 \\
3 & 0,435 & 339,0 & 88,0 & 76,0 \\
\hline Média & 0,429 & 341,0 & 88,0 & 76,0 \\
\hline
\end{tabular}

O processo de compostagem foi conduzido em pátio com piso de concreto, declividade de $2 \%$ para escoamento da umidade excessiva e cobertura plástica para proteger da incidência solar direta e das chuvas.

No ensaio de compostagem, foram monitorados: temperatura, peso, teores de ST e SV, volume (com uso de baldes graduados) ocupado pelas leiras, semanalmente, e coliformes totais e termotolerantes no início, aos 35 dias e ao final do processo.

Os teores de ST e SV das amostras coletadas durante o ensaio de compostagem foram determinados de acordo com metodologia descrita por APHA (2005). Os NMPs de coliformes totais e termotolerantes foram avaliados no início, durante e ao final do processo de compostagem por meio da técnica de tubos múltiplos, a partir de metodologia proposta pela APHA (2005).

As amostras coletadas durante o desenvolvimento do experimento de compostagem foram pré-secadas a $60^{\circ} \mathrm{C}$, em estufa de circulação forçada de ar, por 48 horas. A seguir, foram finamente moídas, em moinho de facas, e então utilizadas para a digestão da matéria orgânica.

Para a digestão, utilizou-se do digestor Digesdahl Hach, que promove a digestão total da matéria orgânica à base de ácido sulfúrico $\left(\mathrm{H}_{2} \mathrm{SO}_{4}\right)$ e peróxido de hidrogênio $\left(\mathrm{H}_{2} \mathrm{O}_{2}\right)$ a $50 \%$.

Com o extrato obtido da digestão sulfúrica, foi possível efetuar a determinação dos teores de nitrogênio, fósforo, potássio, cálcio, magnésio, sódio, ferro, cobre, zinco e manganês, segundo APHA (2005). O nitrogênio foi determinado conforme metodologia descrita por SILVA \& QUEIROZ (2006). Os teores de fósforo foram determinados pelo método colorimétrico utilizando-se de espectrofotômetro HACH, modelo DR-2000. O método baseia-se na formação de composto amarelo do sistema vanadomolibdofosfórico em acidez de 0,2 a 1,6 N, no qual a cor desenvolvida é medida em espectrofotômetro, determinando-se, assim, a concentração de fósforo das amostras, por meio da utilização de uma reta-padrão traçada previamente a partir de concentrações conhecidas,

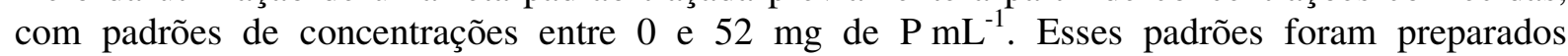
conforme metodologia descrita por APHA (2005). As concentrações de $\mathrm{K}, \mathrm{Ca}, \mathrm{Mg} \mathrm{Na}, \mathrm{Fe}, \mathrm{Cu}, \mathrm{Zn}$ e Mn foram determinadas em espectrofotômetro de absorção atômica, modelo GBC 932 AA.

A partir das amostras coletadas nas leiras de compostagem, no início e na finalização do processo, foram quantificados os teores de $\mathrm{C}$ orgânico, cuja análise se fundamenta no fato de a matéria orgânica oxidável ser atacada pela mistura sulfocrômica, utilizando-se do próprio calor 
formado pela reação do dicromato de potássio com o ácido sulfúrico como fonte calorífica. O excesso de agente oxidante que resta desse ataque é determinado por titulação com sulfato ferroso.

O método oferece a vantagem de não oxidar a fração de matéria orgânica não decomponível durante o processo de compostagem (KIEHL, 1985). Os conteúdos de matéria orgânica compostável (MOC), matéria orgânica resistente à compostagem (MORC) e demanda química de oxigênio (DQO) foram estimados conforme as equações propostas por KIEHL (1985).

\section{RESULTADOS E DISCUSSÃO}

\section{Temperatura e redução de coliformes termotolerantes e totais}

Os resultados que se referem ao acompanhamento da temperatura durante o período de compostagem estão representados na Figura 1. Esse parâmetro é considerado como fator determinante na eficiência do processo sobre a redução das características poluentes do resíduo e, por isso, tradicionalmente, utilizado como indicador do desempenho da compostagem.

Independentemente do material que será utilizado como substrato para o processo de compostagem, a USEPA, citada por LAU et al. (1992), recomenda que a temperatura no interior da leira atinja, no mínimo, $55^{\circ} \mathrm{C}$ e mantenha-se nessa faixa por, pelo menos, três dias consecutivos, para que o número de patógenos atinja níveis aceitáveis, permitindo a aplicação no solo. Por essa razão, a temperatura deve ser acompanhada durante todo o processo de compostagem.

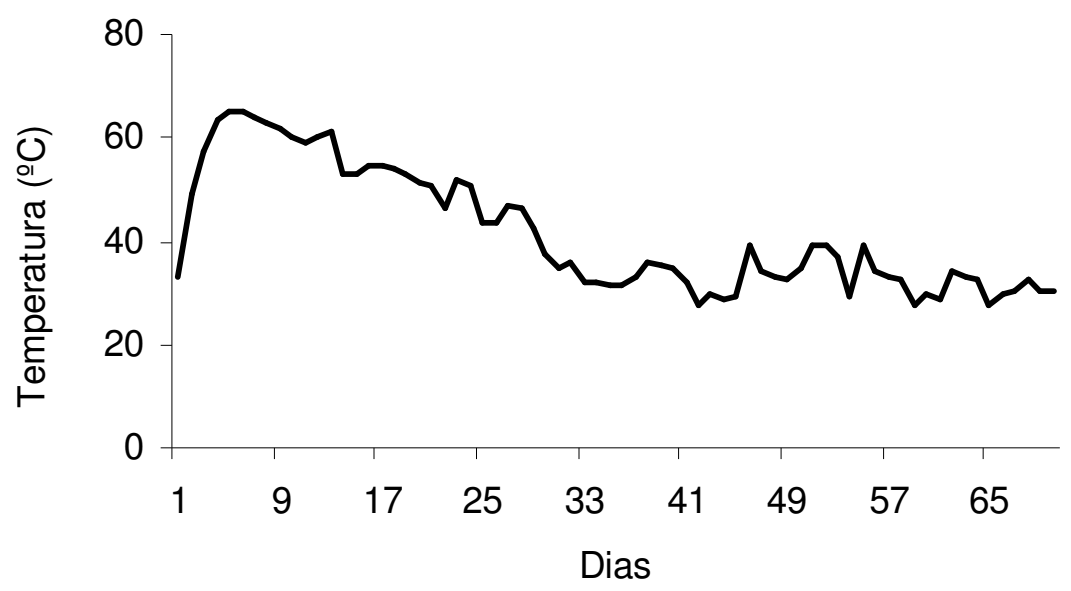

FIGURA 1. Temperatura média observada durante a compostagem do material retido na peneira de $1 \mathrm{~mm}$. Medium temperature during the composting of the material retained on the sieve of $1 \mathrm{~mm}$.

A compostagem da fração sólida dos dejetos de suínos permaneceu com temperaturas superiores a $40{ }^{\circ} \mathrm{C}$ do segundo até o $29^{\circ}$ dia de enleiramento, e o pico de temperatura foi de $65^{\circ} \mathrm{C}$ e ocorreu no quinto dia. LO et al. (1993) estudaram a fração sólida dos dejetos de suínos com e sem adição de resíduos vegetais e encontraram valores inferiores ao observado neste trabalho, sendo o pico máximo de temperatura de $55^{\circ} \mathrm{C}$, e a temperatura permaneceu acima dos $40^{\circ} \mathrm{C}$ até o sétimo dia de enleiramento.

A análise microbiológica demonstrou a eficiência da compostagem na remoção de coliformes durante o período de enleiramento (Tabela 2). A redução dos números de patógenos no produto final, que será retornado ao solo, é um fator importante, pois a ocorrência de altos níveis de bactérias do grupo coliformes na água de consumo pode sujeitar as propriedades a maiores taxas de incidência de doenças nos animais, com consequente aumento da mortalidade e diminuição da produtividade (GONÇALVES \& MARIN, 2007). 
TABELA 2. Redução de coliformes totais e termotolerantes durante a compostagem da fração retida na peneira. Reduction of total and thermotolerant coliforms during the composting of the fraction retained on the sieve.

\begin{tabular}{ccc}
\hline Período & Coliforme Total (NMP) & Coliforme Termotolerante (NMP) \\
\hline Início & $4,310^{7}$ & $2,310^{7}$ \\
35 dias & 3,6 & 3,6 \\
Final & 0,0 & 0,0 \\
\hline Redução \% & 100,00 & 100,00 \\
\hline
\end{tabular}

ZHU et al. (2004), ao estudarem a compostagem de esterco de suíno com resíduos de colheita, observaram que, após 63 dias da compostagem, $100 \%$ das E. coli e ovos de helmintos haviam sido destruídos. Vários trabalhos, como os de CURCI et al. (2007), TORRES et al. (2007) e ORRICO et al. (2007), também observaram a eficiência da compostagem na eliminação de microrganismos patogênicos.

\section{Reduções de volume e massa}

Nas Figuras 2 e 3, podem ser observadas as reduções de sólidos totais e de volume durante a compostagem do material retido na peneira.

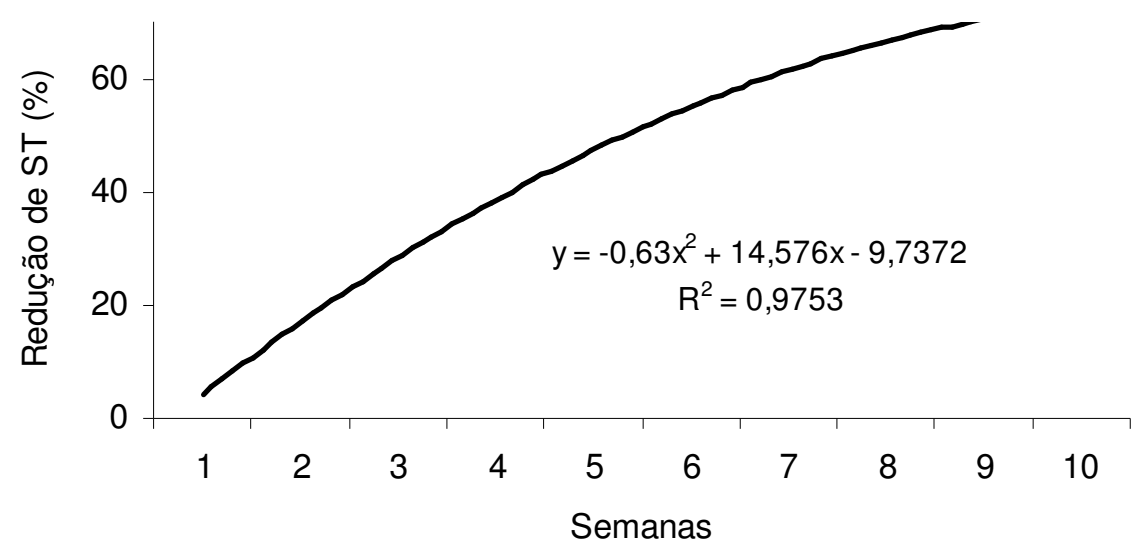

FIGURA 2. Redução de ST observada durante a compostagem do material retido na peneira de $1 \mathrm{~mm}$. Reduction of TS observed during the composting of the material retained on the sieve of $1 \mathrm{~mm}$.

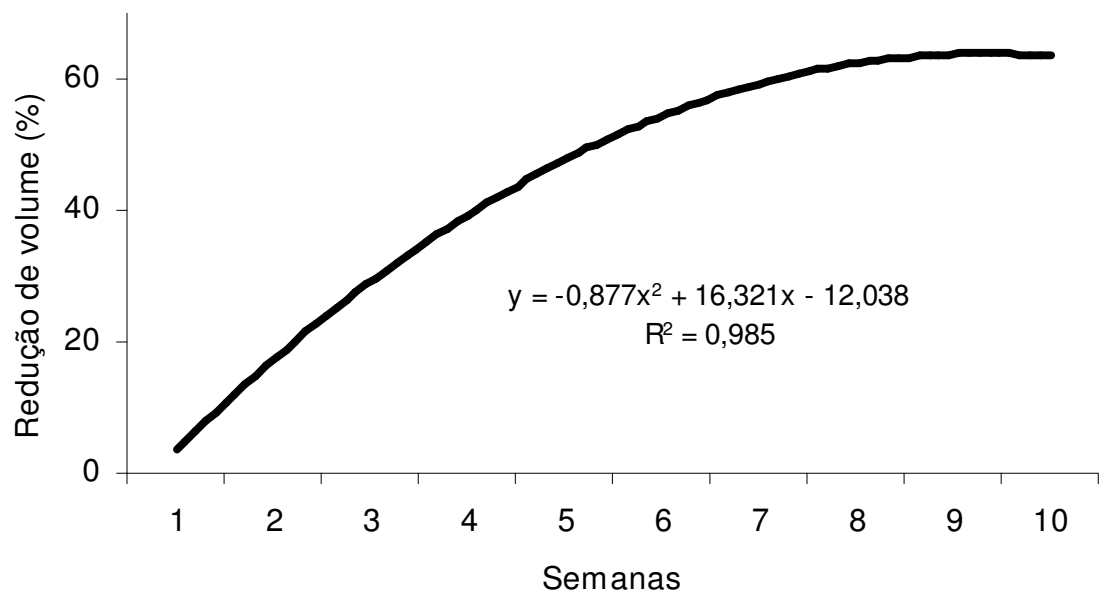

FIGURA 3. Redução de volume observada durante a compostagem do material retido na peneira de $1 \mathrm{~mm}$. Reduction in volume observed during the composting of the material retained on the sieve of $1 \mathrm{~mm}$. 
As reduções de volume e de sólidos totais observadas durante a compostagem apresentaram o mesmo comportamento, quadrático, visto que uma variável está diretamente correlacionada à outra, pois a perda de massa seca é demonstrada pela redução do volume ocupado pela leira. ORRICO JÚNIOR et al. (2003), ao utilizarem resíduos provenientes de granja leiteira como substrato para compostagem, observaram que a redução de volume obedecia a um comportamento quadrático, ou seja, redução acentuada nas primeiras semanas de enleiramento seguida de desaceleração gradual até o fim do processo. No entanto, AMORIM et al. (2004) avaliaram a redução de volume em leiras formadas com dejetos de cabras e conduzidas durante as quatro estações do ano e constataram reduções lineares nos volumes ocupados pelas leiras.

As maiores reduções de ST e de volume (Tabela 3) ocorreram na primeira semana do processo, e a eficiência na degradação de ST do material chegou a 71,24\%.

Segundo AMORIM et al. (2004), um importante índice é a redução de massa seca; nesse sentido, os autores observaram maiores reduções $(\mathrm{P}<0,05)$ em leiras conduzidas durante as estações de verão e outono (com médias de 54,6 e 51,6\%, respectivamente), em relação às manejadas durante o inverno e primavera, médias de 49,2 e $48,8 \%$, respectivamente.

Esses valores podem ser comparados aos obtidos por GORGATI (2001), em trabalho realizado com compostagem de lixo urbano, o qual obteve reduções médias de 53,1 e 52,9\% em leiras cobertas e descobertas, respectivamente. KIEHL (1985) definiu que a redução esperada deve ser de aproximadamente $50 \%$.

TABELA 3. Reduções de massa e de volume observadas durante a compostagem da fração sólida dos dejetos de suínos. Reductions in mass and volume observed during the composting of solid fraction of pig manure.

\begin{tabular}{ccccc}
\hline \multirow{2}{*}{ Semanas } & Volume & ST & \multicolumn{2}{c}{ Redução (\%) } \\
\cline { 2 - 5 } & $\left(\mathrm{m}^{3}\right)$ & $(\mathrm{kg})$ & ST & Volume \\
\hline Início & 0,428 & 88,24 & 0,00 & 0,00 \\
1 & 0,327 & 63,68 & 23,51 & 23,51 \\
2 & 0,314 & 60,67 & 31,24 & 26,73 \\
3 & 0,264 & 57,09 & 35,30 & 38,23 \\
4 & 0,219 & 51,39 & 41,76 & 48,85 \\
5 & 0,200 & 39,00 & 55,80 & 53,33 \\
6 & 0,174 & 33,60 & 61,92 & 59,23 \\
7 & 0,162 & 26,66 & 69,78 & 62,15 \\
8 & 0,156 & 25,31 & 71,32 & 63,48 \\
9 & 0,154 & 25,45 & 71,16 & 64,08 \\
10 & 0,152 & 25,37 & 71,24 & 64,55 \\
\hline
\end{tabular}

\section{Teores de carbono, nitrogênio, relação C: N, MOC, MORC e DQO}

$\mathrm{Na}$ Tabela 4, estão apresentados os resultados dos teores de C, N, relação C:N, MOC, MORC e DQO no substrato inicial da compostagem e no produto final. Na Tabela 5, estão apresentados os teores de macro e micronutrientes verificados durante a compostagem, assim como suas concentrações observadas durante o período.

A relação $\mathrm{C} / \mathrm{N}$ do composto (final) apresentou-se inferior à definida como ideal por LOPEZREAL (1990), citado por GORGATI (2001), que foi de 10:1. No entanto, GORGATI (2001) encontrou no composto obtido de lixo urbano relação $\mathrm{C}$ : $\mathrm{N}$ de 6,6 em leiras cobertas. Essas diferenças, provavelmente, possam ser atribuídas à qualidade dos substratos e, consequentemente, à facilidade de degradação, visto que a relação tida como ideal foi estabelecida com base na hierarquia básica de decomposição, preconizada por KIEHL (1985), juntamente com diversos resultados encontrados em experimentos de compostagem, conduzidos, na maioria das vezes, com substratos contendo fontes vegetais (palhadas e/ou restos de culturas). Já as relações C:N obtidas 
neste experimento e por GORGATI (2001) foram com base em substratos mais facilmente degradáveis do que palhadas e restos de culturas.

TABELA 4. Teores de $\mathrm{C}$ (carbono), $\mathrm{N}$ (nitrogênio), relação $\mathrm{C}$ : $\mathrm{N}, \mathrm{MOC}$ (matéria orgânica compostável), MORC (matéria orgânica resistente à compostagem) e DQO (demanda química de oxigênio), assim como suas respectivas reduções durante a compostagem da fração sólida dos dejetos de suínos. Levels of $\mathbf{C}$ (carbon), $\mathbf{N}$ (nitrogen), C: N, MOC (compostable organic matter), MORC (resistant to composting organic matter) and COD (chemical oxygen demand), as well as their respective reductions during the composting solid fraction of pig manure.

\begin{tabular}{crrrrrr}
\hline \multirow{2}{*}{ Período } & \multicolumn{1}{c}{$\mathrm{C}$} & $\mathrm{N}$ & $\mathrm{C} / \mathrm{N}$ & MOC & MORC & DQO $\left(\mathrm{g} \mathrm{kg}^{-1}\right)$ \\
\cline { 2 - 7 } & \multicolumn{7}{c}{ \% dos ST } \\
\hline Inicial & 16,70 & 3,36 & 4,97 & 30,06 & 56,39 & 445,22 \\
Final & 7,20 & 2,74 & 2,62 & 12,96 & 51,43 & 191,95 \\
\hline Redução (\%) & 56,89 & 18,37 & 47,19 & 56,89 & 8,80 & 56,89 \\
\hline
\end{tabular}

Observa-se que, independentemente do nutriente avaliado, com exceção do $\mathrm{N}$, houve correspondência entre as reduções de massa seca obtidas com a compostagem e a concentração de nutrientes (Tabela 5). Essa ocorrência revela os cuidados adotados durante a compostagem, como evitar a exposição das leiras às chuvas ou que ficassem excessivamente úmidas e assim favorecesse a formação de chorume, com consequente escoamento superficial e/ou lixiviação de nutrientes.

TABELA 5. Teores (em \% dos STs) e respectivas concentrações de macro e micronutrientes durante a compostagem da fração sólida dos dejetos de suínos. Levels (in \% of TS) and their concentrations of macro and micronutrients during the composting of solid fraction of pig manure.

\begin{tabular}{lccccc}
\hline \multirow{2}{*}{ Período } & \multicolumn{5}{c}{$\%$ dos ST } \\
\cline { 2 - 6 } & $\mathrm{N}$ & $\mathrm{P}$ & $\mathrm{K}$ & $\mathrm{Ca}$ & $\mathrm{Mg}$ \\
\hline Inicial & 3,361 & 1,960 & 1,021 & 1,903 & 0,502 \\
Final & 2,744 & 3,997 & 1,937 & 3,510 & 0,706 \\
\hline Concentração (\%) & $-22,50$ & 50,96 & 47,27 & 45,79 & 28,90 \\
\hline \multirow{2}{*}{ Período } & $\mathrm{Na}$ & $\mathrm{Fe}$ & $\mathrm{Cu}$ & $\mathrm{Zn}$ & $\mathrm{Mn}$ \\
\hline Inicial & 0,226 & 0,141 & 0,057 & 0,097 & 0,048 \\
Final & 0,341 & 0,260 & 0,095 & 0,128 & 0,092 \\
\hline Concentração $(\%)$ & 33,55 & 45,82 & 40,13 & 24,59 & 47,48 \\
\hline
\end{tabular}

Esse comportamento não foi observado por AMORIM et al. (2004) quando conduziram leiras de compostagem a partir dos dejetos de caprinos, notando, inclusive, redução nos teores de nutrientes do composto em relação ao material inicial. As maiores reduções encontradas foram nas concentrações de $\mathrm{P}, \mathrm{Ca}$ e $\mathrm{Na}(59,3 ; 54,6$ e 57,8\%, respectivamente) em leiras conduzidas durante o verão, com relação às demais estações. Os autores associaram esse comportamento com a formação de chorume no período inicial de compostagem.

EGHBALL (1997) avaliou as perdas ocorridas durante o processo de compostagem, utilizando-se como substrato de esterco bovino. O material permaneceu enleirado por 45 dias e, ao final deste período, apresentou perdas de 42,$5 ; 0,8 ; 15,8 ; 15,5 ; 1,6$ e $1,9 \%$ para $\mathrm{N}, \mathrm{P}, \mathrm{K}, \mathrm{Na}, \mathrm{Ca}$ e $\mathrm{Mg}$, respectivamente, e redução de massa de 20,4\%. Tomando-se por base esse último valor, acredita-se que o período de enleiramento tenha sido insuficiente, pois a redução de massa esperada seria de $50 \%$. 


\section{CONCLUSÕES}

Os resultados apresentados mostraram que a compostagem pode ser utilizada no tratamento da fração sólida da água residuária de suinocultura, visto que o processo foi eficiente na redução do poder poluente dos dejetos, principalmente na quantidade de ST, volume, DQO, MOC e coliformes. Entretanto, o processo não foi tão eficiente na conservação do nitrogênio que, por características próprias do material, acarretaram significativas perdas desse nutriente.

\section{REFERÊNCIAS}

APHA. AMERICAN PUBLIC HEALTH ASSOCIATION. Standard methods for examination of water and wastewater. $21^{\text {th }}$ ed. Washington: American Water Works Association, 2005. $1.368 \mathrm{p}$.

AMORIM, A.C.; LUCAS JÚNIOR, J.; RESENDE, K.T. Biodigestão anaeróbia de dejetos de caprinos obtidos nas diferentes estações do ano. Engenharia Agrícola, Jaboticabal, v.24, n.1, p.16$-24,2004$.

CURCI, V.C.L.M.; DUTRA, I.S.; DOBEREINER, J.; LUCAS JÚNIOR, J. Pré-compostagem de cadáveres de bovinos acometidos pelo botulismo. Pesquisa Veterinária Brasileira, Rio de Janeiro, v.27, n.4, p.157-161, 2007.

EGHBALL, B. Nutrient, Carbon and mass loss during composting of beef cattle feedlot manure. Journal Environmental Quality, Madison, v.26, n.1, p.189-193, 1997.

GONÇALVES, V.P.; MARIN, J.M. Fate of non O157 Shiga toxigenic Escherichia coli in composted cattle manure. Arquivos Brasileiros de Medicina Veterinária e Zootecnia, Belo Horizonte, v.59, n.4, p.825-831, 2007.

GORGATI, C.Q. Resíduos sólidos urbanos em área de proteção aos mananciais - município de São Lourenço da Serra - SP: compostagem e impacto ambiental. 2001.74 f. Tese. (Doutorado em Energia na Agricultura) - Faculdade de Ciências Agronômicas, Universidade Estadual Paulista, Botucatu, 2001.

KIEHL, E. J. Fertilizantes orgânicos. São Paulo: Agronômica Ceres, 1985. 492 p.

LAU, A.K.; LO, K.V.; LIAO, P.H.; YU, J.C. Aeration experiments for swine waste composting. Bioresource Technology, Oxford, v.41, n.2, p.145-152, 1992.

LO, K.V.; LAU, A.; LIAO, P.H. Composting of separated solid swine waste. Journal of Agricultural Engeenering Research, London, v.54, n.4, p.307-317, 1993.

ORRICO JÚNIOR, M.A.P.; AMORIM, A.C.; LUCAS JÚNIOR, J. Compostagem e vermicompostagem de dejetos de vacas leiteiras. In: CONGRESSO BRASILEIRO DE ENGENHARIA AGRÍCOLA, 32., 2003, Goiânia. Anais... Jaboticabal: SBEA, 2003. 1 CD-ROM.

ORRICO, A.C.A.; LUCAS JÚNIOR, J.; ORRICO JÚNIOR, M.A.P. Alterações físicas e microbiológicas durante a compostagem dos dejetos de cabras. Engenharia Agrícola, Jaboticabal, v.27, n.3, p.764-772, 2007.

RICO, J.L.; GARCIA, H.; RICO, C.; TEJERO, I. Characterization of solid and liquid fractions of dairy manure with regard to their component distribution and methane production. Bioresource Technology, Oxford, v.98, n.5, p.971-979, 2006.

SILVA, D.J.; QUEIROZ, A.C. Análise de alimentos: métodos químicos e biológicos. 3.ed. Viçosa: Editora Universitária, 2006. 166 p.

TORRES, P.; PÉREZ, A.; ESCOBAR, J.C.; URIBE, I.U.; IMERY, R. Compostaje de biosólidos de plantas de tratamiento de águas residuales. Engenharia Agrícola, Jaboticabal, v.27, n.1, p.267-275, 2007. 
ZHU, N. Effect of low initial C/N ratio on aerobic composting of swine manure with rice. Bioresource Technology, Oxford, v.98, n.1, p.9-13, 2007.

ZHU, N.; CHANGYAN, D.; YUANZHU, X.; HUIYUE, Q. Performance characteristics of three aeration systems in the swine manure composting. Bioresource Technology, Oxford, v.95, n.3, p.319-326, 2004. 